\title{
Lipid signaling and fat storage in the dark-eyed junco
}

Jacqueline M. Ho ${ }^{\mathrm{a}, \mathrm{b}^{*}}$, Christine M. Bergeon Burns ${ }^{\mathrm{a}, \mathrm{b}}$, Nikki M. Rendon ${ }^{\mathrm{a}, \mathrm{b}}$, Kimberly A. Rosvall $^{\mathrm{a}, \mathrm{b}, \mathrm{c}}$, Heather B. Bradshaw ${ }^{\mathrm{b}, \mathrm{c}, \mathrm{d}}$, Ellen D. Ketterson ${ }^{\mathrm{a}, \mathrm{b}}$ and Gregory E. Demas ${ }^{\mathrm{a}, \mathrm{b}, \mathrm{c}}$ 
1 Abstract

2

3 Seasonal hyperphagia and fattening promote survivorship in migratory and wintering birds, but

4 reduced adiposity may be more advantageous during the breeding season. Factors such as

5 photoperiod, temperature, and food predictability are known environmental determinants of fat

6 storage, but the underlying neuroendocrine mechanisms are less clear. Endocannabinoids and

7 other lipid signaling molecules regulate multiple aspects of energy balance including appetite

8 and lipid metabolism. However, these functions have been established primarily in mammals;

9 thus the role of lipid signals in avian fat storage remains largely undefined. Here we examined

10 relationships between endocannabinoid signaling and individual variation in fat storage in

11 captive white-winged juncos (Junco hyemalis aikeni) following a transition to long-day

12 photoperiods. We report that levels of the endocannabinoid 2-arachidonoylglycerol (2-AG), but

13 not anandamide (AEA), in furcular and abdominal fat depots correlate negatively with fat mass.

14 Hindbrain mRNA expression of $\mathrm{CB}_{1}$ endocannabinoid receptors also correlates negatively with

15 levels of fat, demonstrating that fatter animals experience less central and peripheral

16 endocannabinoid signaling when in breeding condition. Concentrations of the anorexigenic lipid,

17 oleoylethanolamide (OEA), also inversely relate to adiposity. These findings demonstrate unique

18 and significant relationships between adiposity and lipid signaling molecules in the brain and

19 periphery, thereby suggesting a potential role for lipid signals in mediating adaptive levels of fat

20 storage.

22 Key words: fattening, adiposity, endocannabinoid, $\mathrm{CB}_{1}$, oleoylethanolamide, 23 palmitoylethanolamide 


\section{Introduction}

Many species accumulate energy stores in anticipation of prolonged periods of increased energy

29 demand or decreased food availability. In passerines, this primarily occurs prior to autumn or

30 vernal migration and during winter (Baldwin and Kendeigh, 1938; Berthold, 1993). Benefits

31 conferred by greater fat storage (e.g., fasting capacity) are tempered by costs that include

32 increased energetic demands of flight (Freed, 1981), loss of agility (Blem, 1975), and greater

33 predation risk with higher foraging rates (Lima, 1986). Thus, individuals must effectively

34 balance this trade-off to maximize survivorship benefits at minimal cost (Rogers, 2015). As a

35 result, fat stores are reduced as birds complete gonadal development and enter the breeding life-

36 history stage (Williams, 2012). The timing and extent of winter fattening are driven by

37 environmental factors such as temperature (Rogers, 1995), food abundance and predictability

38 (Rogers and Smith, 1993; Witter et al., 1995; Biebach, 1996), and climate (Nolan and Ketterson,

39 1983), whereas migratory fattening follows a circannual rhythm predominantly synchronized by

40 changes in photoperiod (Gwinner, 1986; Berthold, 1996).

41 The neuroendocrine mechanisms that mediate seasonal changes in fat are less clear.

42 Studies have typically focused on few physiological systems, and results often suggest complex

43 relationships that may vary by species as well as life-history stage. For example, corticosterone

44 has been suggested to drive changes in feeding and fat deposition during winter in the migratory

45 slate-colored race of the dark-eyed junco (Junco hyemalis hyemalis), a common North American

46 songbird (Gray et al., 1990; Rogers et al., 1993). In contrast, evidence for relationships between

47 corticosterone and pre-migratory fattening in this subspecies have been mixed, and may further

48 be complicated by differences between migratory and resident subspecies (Ramenofsky et al.,

49 1999; Holberton et al., 2007; Holberton et al., 2008; Bauer et al., 2015; Fudickar et al., 2016). In 
50 addition to glucocorticoids, hormones such as testosterone (Lofts and Marshall, 1961; Morton

51 and Mewalt, 1962; Stetson and Erickson, 1972; Schwabl and Farner, 1989; Deviche, 1995) and

52 prolactin (Meier and Farner, 1964; Buntin and Tesch, 1985; Boswell et al., 1995; Holberton and

53 Dufty, 2005) have been associated with feeding and fat regulation in birds. However,

54 neuroendocrine regulators classically implicated in mammalian energy balance such as

55 neuropeptide Y, insulin, and glucagon have been examined to a lesser extent (Totzke et al., 1997;

56 Holberton and Dufty, 2005; Ramakrishnan et al., 2007).

57 Similarly, little is known of energy regulatory functions of endocannabinoids in birds,

58 despite well-established roles of these ubiquitous neuromodulators in mammalian food intake

59 (Pagotto et al., 2006), lipogenesis (Osei-Hyiaman et al., 2005; Vettor and Pagano, 2009), and

60 energy expenditure (Cluny et al., 2010; Quarta et al., 2010; Tam et al., 2010). Endocannabinoids

61 are produced locally and on demand in the brain and periphery. They are capable of fine-tuning

62 synaptic transmission by activating $\mathrm{CB}_{1}$ receptors on presynaptic axons to inhibit transmitter

63 release (Di Marzo et al., 2005). The appetite-stimulating effects of endocannabinoids are in part

64 due to such retrograde inhibition of classical hypothalamic circuits (Jo et al., 2005). Moreover, in

65 vivo and in vitro models suggest that peripheral endocannabinoid signaling promotes fat

66 deposition by stimulating glucose uptake and lipogenesis via adipocyte $\mathrm{CB}_{1}$ receptors (Cota et

67 al., 2003; Jbilo et al., 2005; Pagano et al., 2007). Although relatively few studies have examined

68 endocannabinoid signaling in birds, existing reports suggest similar functions to those observed

69 in mammals, including promotion of food intake in chickens (Novoseletsky et al., 2011) and

70 inhibition of hypothalamo-pituitary-adrenal (HPA) activity in European starlings (Dickens et al.,

71 2015). Because hyperphagia is the primary means to increase fat stores in birds (King et al.,

72 1963; King, 1972; Baggott, 1975; Blem, 1980; Piersma and Jukema, 1990), the endocannabinoid 
73 system is a prime candidate to maintain plasticity and seasonally appropriate levels of food

74 intake and fat storage.

In the present study, we examined the endocannabinoid system in relation to fat stores in

76 captive dark-eyed juncos acclimating to long days. Specifically, we determined whether

77 individual variation in adiposity of two major fat depots relate to local concentrations of the

78 endocannabinoids 2-arachidonoylglycerol (2-AG) and anandamide (AEA). To determine

79 whether central endocannabinoid signaling contributes to fat levels, we quantified mRNA

80 expression of $\mathrm{CB}_{1}$ receptors in the hindbrain, a brain region that regulates feeding in birds

81 (Dubbeldam, 1984; Boswell et al., 1995; Moghaddam et al., 2010) and mammals (Berthoud,

82 2004). Given $\mathrm{CB}_{1}$ receptors' ability to promote food intake in birds (Novoseletsky et al., 2011),

83 we predicted that central $\left(\mathrm{CB}_{1}\right)$ and peripheral (2-AG; AEA) endocannabinoid signaling would

84 relate positively to fat levels in the present study. We also predicted that concentrations of

85 oleoylethanolamide (OEA) and palmitoylethanolamide (PEA), two structurally-related lipids

86 with opposing effects on energy balance from those of endocannabinoids (Rodriguez de Fonseca

87 et al., 2001), would correlate negatively with adiposity. However, if the relationship between

88 lipid signaling and adiposity is dependent on current energetic need, then an alternative

89 prediction is that fat levels would negatively correlate with orexigenic lipid signaling in contexts

90 of fat loss, such as during preparation for breeding.

91

92

93

94

95

96 Thirty-five male and female dark-eyed juncos (subspecies: white-winged junco, Junco hyemalis

97 aikeni) were captured as juveniles in the Black Hills National Forest near Custer, South Dakota

$98\left(43^{\circ} 46^{\prime} \mathrm{N}, 103^{\circ} 36^{\prime} \mathrm{W}\right)$ at the end of the 2009 breeding season. Juncos were caught using baited 
99 mist-nets and potter traps. The birds were banded, measured, bled from the wing vein upon

100 capture, and group-housed in a temporary outdoor aviary in the field. In early August, they were

101 transported to Indiana University $\left(39^{\circ} 09^{\prime} \mathrm{N}, 86^{\circ} 31^{\prime} \mathrm{W}\right)$ where they were group-housed in an

102 indoor aviary held around $16^{\circ} \mathrm{C}$ and maintained on a diet of ad libitum millet, sunflower seeds,

103 orange slices, mealworms (Tenebrio molitor), and a mixture of puppy chow, hardboiled eggs,

104 and carrots. From August through February, the free-flying birds were captured approximately

105 every 2-3 weeks (17 \pm 1 days) and subcutaneous fat was visually scored using established criteria

106 (Rogers, 1991) as outlined in Table 1. Photoperiod was adjusted every two weeks to match the

107 naturally changing photoperiod at their capture site. This allowed birds to molt and become

108 photosensitive during spring 2010. In the wild, this subspecies overwinters at lower elevations

109 extending from the breeding range in the Black Hills into the foothills of the nearby Rocky

110 Mountains (Whitney, 1968; eBird, 2016). Thus, the duration of this study tracked a period of

111 time during which birds naturally fatten over winter and lose fat as they enter breeding condition.

112 During the first week of March 2010, before natural photoperiod reached a stimulatory

113 day length, biweekly photoperiod adjustments were discontinued and photoperiod was increased

114 by $1 \mathrm{~h}$ every two days until a 16:8 h light:dark cycle was achieved (March 10). Birds remained

115 on this long-day photoperiod for the duration of this study (through mid-April). During this time,

116 birds were individually housed across four similarly-sized, mixed-sex housing rooms. This rapid

117 increase in photoperiod is sufficient to initiate gonadal growth and loss of winter fat (Dawson et

118 al., 2001; Bergeon Burns et al., 2014; Rosvall et al., 2016), but allows for variation in the rate at

119 which birds adjust fat levels. For this study, we capitalized on this individual variation to

120 examine birds that vary in degree of fat storage and pre-breeding fat loss. Juncos had high

121 survivorship and maintained excellent physical condition in captivity. Thirty-two individuals (19 
122 males, 13 females) were used in this study. All procedures were approved by the Bloomington

123 Institutional Animal Care and Use Committee (BIACUC) at Indiana University.

124

125

126

127

128

129 138 individuals.

\subsection{Tissue collection}

Prior to tissue collection for the present study, all birds participated in a separate experiment in which they received a series of three hormone challenges (two of chicken gonadotropin-releasing hormone, one of ovine luteinizing hormone) separated by five-day intervals. Small blood samples $(100 \mu \mathrm{l})$ were collected before and shortly after hormone administration to assess transient hormone responses (Rosvall et al., 2013; Bergeon Burns et al., 2014). All birds were exposed to the same manipulations and these hormone challenges evoke only a short-term hormonal response that returns to basal condition within hours (Jawor et al., 2006; Rosvall et al., 2016). Basal hormone levels do not differ significantly between challenges separated by five-day intervals (Bergeon Burns et al., 2014), suggesting that five days is of sufficient duration for birds to return to basal physiological condition. Variation in the present measures of interest at the time of sample collection can therefore be reasonably attributed to natural variation among

Five days after the final hormone challenge (in mid-April; 38d after reaching 16L:8D), birds were overdosed with isoflurane inhalation and decapitated. Brains and gonads were quickly extracted under RNase-free conditions and immediately frozen on crushed dry ice. Visual analyses of gonads revealed that all birds were in reproductive condition and had testosterone concentrations comparable to free-living birds in the early breeding season (Rosvall et al., 2013; Bergeon Burns et al., 2014). Each bird was assigned a fat score by visual assessment, as before. Fat depots from the furculum and abdomen were then excised, weighed, and frozen on dry ice. Samples were stored at $-80^{\circ} \mathrm{C}$ until further microdissection (brains) or processing (fat). 


\subsection{Compound extraction from fat samples}

Tissues were processed based on a protocol previously described (Bradshaw et al., 2006).

151 Briefly, fat samples ( 0.08 g) were incubated on ice with 50 volumes of $100 \%$ HPLC-grade

152 methanol for $1 \mathrm{~h}$. One hundred pmol $\left[{ }^{2} \mathrm{H}_{8}\right]$-anandamide (Cayman Chemical, Ann Arbor, MI) was

153 added to the methanol/tissue sample and used as an internal standard to track recovery of the test

154 compounds. Following incubation, samples were maintained on ice and homogenized (Polytron

155 PT 10-35) for 1-2 min. Samples were centrifuged at $42,858 \mathrm{x}$ g and $24^{\circ} \mathrm{C}$ for $20 \mathrm{~min}$.

156 Supernatants were collected and diluted to a $25 \%$ organic solution with HPLC-grade water.

157 Compounds were partially purified from the supernatant using $500 \mathrm{mg} \mathrm{C} 18$ solid phase

158 extraction columns (Varian \#12113027, Harbor City, CA), conditioned with 5 ml 100\% HPLC-

159 grade methanol and $2.5 \mathrm{ml} \mathrm{HPLC}$ water prior to addition of the water/supernatant solution.

160 Columns were washed with $2.5 \mathrm{ml}$ of HPLC-grade water and three elutions were collected (1.5

$161 \mathrm{ml}$ each of 65,80 , and $100 \%$ HPLC-grade methanol). Elutions were stored at $-20^{\circ} \mathrm{C}$ until mass

162 spectrometric analysis. Individual furcular and abdominal fat samples were processed separately

163 with both sexes analyzed within each batch.

164

\subsection{HPLC/MS/MS analysis and quantification of lipid signalers}

167 Each elution was warmed to room temperature and vortexed prior to mass spectrometric

168 analysis. Rapid separation was obtained with 10-20 $\mu$ l injections of analyte (CBM-20A

169 prominence controller and SIL-20AC prominence autosampler; Shimadzu, Columbia, MD;

170 maintained at $24^{\circ} \mathrm{C}$ ) onto a Zorbax eclipse XDB 2.1x50 mm reversed phase column. Gradient

171 elution (methanol and water; $200 \mu \mathrm{l} / \mathrm{min}$ ) was formed under pressure on a pair of 10AdVP

172 pumps (Shimazdu). Mass spectrometric analysis was performed using electrospray ionization 
173 with a triple quadrupole mass spectrometer (API3000, Applied Biosystems/MDS Sciex, Foster

174 City, CA). Levels of each compound were analyzed by multiple reactions monitoring on the

$175 \mathrm{HPLC} / \mathrm{MS} / \mathrm{MS}$ system. In this mode, detection of each compound is based on fragmentation of a

176 precursor ion $[\mathrm{M}+\mathrm{H}]^{+}$or $[\mathrm{M}-\mathrm{H}]^{+}$to yield a prominent product ion. Mass spectrometric conditions

177 were optimized for each compound using direct flow injection of synthetic standards of each

178 compound (Cayman Chemical). Test compounds of interest were the endocannabinoids 2-AG

179 and AEA as well as non-cannabinoid but structurally-related $N$-acyl ethanolamides, OEA and

180 PEA.

181

182

183

184 Brains were microdissected into functional regions following Soma et al. (1999), and hindbrain

185 was reserved for this study. Hindbrain tissue was homogenized for $30-45 \mathrm{~s}$ to isolate total RNA

186 using TRIzol reagent (Invitrogen, Carlsbad, CA) according to manufacturer instructions. RNA

187 concentration was determined using a spectrophotometer and RNA integrity was verified by gel

188 electrophoresis. All RNA samples were stored at $-80^{\circ} \mathrm{C}$ until further analysis. Following DNase

189 treatment (Invitrogen), $1 \mu \mathrm{g}$ RNA was reverse transcribed into cDNA in $20 \mu \mathrm{l}$ total volume

190 according to manufacturer instructions using oligo dT primers and Superscript III Reverse

191 Transcriptase (Invitrogen), yielding a stock concentration of $50 \mathrm{ng} / \mu \mathrm{l}$.

192

193

194

195 To ensure high specificity of primers, a portion of the gene for $\mathrm{CB}_{1}$, the primary

196 endocannabinoid receptor in the brain, was sequenced for this species. Initial primers were

197 designed using PrimerQuest (Integrated DNA Technologies, Coralville, IA) from zebra finch

198 (Taeniopygia guttata) $\mathrm{CB}_{1}(\mathrm{GenBank}$ accession no. $\mathrm{AF} 255388.1)$ : forward, 5'- 
AGTGGGACTTCCTCCGATGCATTT-3’; reverse, 5’-

200 ACGATAGCGATGGTCCACATCACA-3'. A $10 \mu$ PCR reaction was performed using $1 \mathrm{X}$

201 GoTaq Flexi DNA polymerase (Promega, Madison, WI), $2.5 \mathrm{mM} \mathrm{MgCl}_{2}, 0.4 \mu \mathrm{M}$ of each primer,

$2020.2 \mathrm{mM}$ of each deoxynucleotide triphosphate (dNTP), $1 \mathrm{U}$ taq, distilled water, and cDNA as a

203 template at a concentration of $5 \mathrm{ng} / \mu \mathrm{l}$. The reaction was carried out at $95^{\circ} \mathrm{C}$ for $2 \mathrm{~min}$, then 30

204 cycles of $95^{\circ} \mathrm{C}$ for $30 \mathrm{sec} / 54^{\circ} \mathrm{C}$ for $30 \mathrm{sec} / 72^{\circ} \mathrm{C}$ for $1.5 \mathrm{~min}$, followed by $72^{\circ} \mathrm{C}$ for $5 \mathrm{~min}$. The

205 reaction amplified an 809-bp product which was confirmed on a 1\% TBE agarose gel containing

206 ethidium bromide. PCR products were purified using a QIAquick PCR purification kit (Qiagen,

207 Valencia, CA) according to manufacturer instructions, sequenced at the Indiana Molecular

208 Biology Institute (Bloomington, IN), and deposited in GenBank (accession no. KX574508).

209 Product sequences were confirmed to be highly homologous to the $\mathrm{CB}_{1}$ sequences for zebra

210 finch (97\%) and the closely-related white-throated sparrow (Zonotrichia albicollis; 99\%) using

211 NCBI BLAST. Junco-specific qPCR primers for $\mathrm{CB}_{1}$ were then designed based on this sequence

212 using PrimerQuest: forward (300 nM), 5' -TTACGTGGGCTCCAACGATATCCA-3'; reverse

213 (300 nM), 5’-TGATGTTGACCTGCTCTGAGGGAA-3’ (amplifying a 179-bp product).

214 Glyceraldehyde-3-phosphate dehydrogenase (GAPDH) served as a reference gene and its

215 primers were based from zebra finch sequence (GenBank accession no. AF255390): forward

216 (300 nM), 5’'TGACCTGCCGTCTGGAAAA-3’' reverse (300 nM), 5'-

217 CCATCAGCAGCAGCCTTCA-3’ (amplifying a 70-bp product). Standard curves with serial

218 dilutions of cDNA resulted in $>0.99$ correlation coefficients and amplification efficiency at

$219 \quad 100.1 \%$ and $109.3 \%$ for $\mathrm{CB}_{1}$ and $\mathrm{GAPDH}$, respectively.

\subsection{Quantitative PCR}

Quantitative PCR was performed on a Stratagene MX3000P qPCR machine by using PerfeCta 
224 SYBR Green SuperMix with Low ROX (Quanta BioSciences, Inc., Gaithersburg, MD). Twenty-

225 five $\mu \mathrm{l}$ reactions were carried out containing half the reaction volume (12.5 $\mu \mathrm{l})$ of SYBR, $12.5 \mathrm{ng}$

226 cDNA, and forward and reverse primers at a concentration of $300 \mathrm{nM}$. Samples were run in

227 duplicate at $95^{\circ} \mathrm{C}$ for $5 \mathrm{~min}, 40$ cycles of $95^{\circ} \mathrm{C}$ for $30 \mathrm{sec} / 60^{\circ} \mathrm{C}$ for $1 \mathrm{~min} / 70^{\circ} \mathrm{C}$ for $30 \mathrm{sec}$,

228 followed by dissociation curves of PCR products to confirm primer specificity.

229 Samples were run across two plates and a common calibrator run on each confirmed low

230 inter-plate variability ( $\% \mathrm{CV}=8.25)$. No template controls were also run in duplicate on each

231 plate and demonstrated no amplification. To quantify $\mathrm{CB}_{1}$ mRNA expression, mean $\mathrm{C}_{\mathrm{T}}$ values

232 were determined between reaction duplicates for each sample. Mean $\mathrm{CB}_{1} \mathrm{C}_{\mathrm{T}}$ values were then

233 normalized to those of an internal reference gene (GAPDH) using the $2^{-\Delta \Delta C T}$ method (Schmittgen

234 and Livak, 2008).

235

236

237

238 Statistical analyses were conducted using SPSS 17.0 (Chicago, IL) and JMP 12.0 (Cary, NC).

239 Pearson correlation coefficients were calculated for all correlational data except for the

240 correlation between fat score and combined fat mass, for which Spearman's rho was calculated

241 instead due to the ordinal nature of fat score. Outliers were determined by Grubbs' test

242 (GraphPad Software, La Jolla, CA) and excluded from analyses. Data from one individual for

243 which lipid concentrations were not detectable in furcular fat were also removed from analyses,

244 resulting in final sample sizes of 30-32. Changes in adiposity over time were quantified using a

245 repeated-measures MANOVA. A post-hoc Welch's ANOVA was used to contrast fat scores in

246 the last score before light advancement (Feb 24) and the final score at the end of the study (April

247 17). Because males and females did not differ in any outcome measure after light advancement, 
data were collapsed across sex for all end-point analyses. Findings were considered significant

249 when $p<0.05$, and we report means \pm SEM unless otherwise noted.

\section{Results}

\subsection{Adiposity}

There was a strong positive correlation between abdominal and furcular fat mass (Fig. 1A; $r=$ 0.936, $p<0.001)$ and between combined fat mass (i.e., abdominal + furcular fat mass) and visual

257 fat score (Fig. 1B; $r=0.912, p<0.001)$ thereby validating the use of this measure in estimating

258 fat levels. White-winged juncos responded to light advancement with significant reductions in 259 adiposity (Welch's ANOVA: $F=6.24, p=0.01$; Fig. 2). Just prior to light advancement, mean

260 fat score was $3.72 \pm 0.30$ and differed significantly between males and females (Repeated 261 measures MANOVA, Date: $F=33.05, p<0.001$; Sex: $F=7.38, p=0.012$; Sex*Date: $F=$

262 2.9256, $p=0.008$ ). After $38 \mathrm{~d}$ in a long-day photoperiod, mean fat score was $2.76 \pm 0.16$ and did 263 not differ between sexes $(t=1.12, p=0.27)$. Based on the relationship between fat score and 264 mass (Fig. 1B), this decline in fat score amounts a loss of almost one gram of fat (average: 0.87

$265 \mathrm{~g}$ ), with some birds gaining up to $0.35 \mathrm{~g}$ and others losing as much as $1.54 \mathrm{~g}$.

\subsection{Lipid signals in adipose tissue}

In general, concentrations of lipid signals corresponded significantly with adiposity levels but

270 did not differ between sexes (all $p>0.1$ ). Individuals with lower amounts of fat tended to have

271 higher levels of 2-AG and OEA. Specifically, furcular 2-AG levels correlated negatively with all

272 three measures of adiposity (i.e., furcular, abdominal, and combined fat mass $)(r=-0.442, p=$

2730.014 for combined fat mass; Fig. 3A), and similar correlations were observed with OEA $(r=-$

$2740.462, p=0.010$ for combined fat mass; Fig. 3C). In contrast, furcular PEA trended towards a 
275 positive correlation with combined fat mass (Fig. 3D; $r=0.322, p=0.082$ ), whereas no

276 associations were observed between furculum-derived AEA and any adiposity measure (Fig. 3B;

$277 p>0.05)$. Concentrations of lipid signals in abdominal fat demonstrated somewhat similar

278 patterns as in the furculum: abdominal 2-AG and OEA correlated negatively with all adiposity

279 measures $(r=-0.557, p=0.001 ; 2-\mathrm{AG}$ and combined fat mass; Fig. 4A), $(r=-0.535, p=0.002$;

280 OEA and combined fat mass; Fig. 4C) whereas abdominal AEA and PEA showed little relation

281 to adiposity (Fig. 4B and D; $p>0.05$ ). In both fat depots, 2-AG and OEA were the only

282 compounds that correlated significantly with each other (furculum: $r=0.371, p=0.048$;

283 abdominal fat: $r=0.509, p=0.004$; all others: $p>0.09, \mathrm{r}<|0.326|)$.

\section{3 $C B_{1}$ expression in hindbrain}

Hindbrain $\mathrm{CB}_{1}$ mRNA expression did not differ between sexes $(p>0.05)$ and correlated

significantly and negatively with abdominal fat mass $(r=-0.364, p=0.044)$. A similar pattern was observed between $\mathrm{CB}_{1}$ mRNA and furcular fat levels $(r=-0.338, p=0.063)$, resulting in a significant negative correlation between hindbrain $\mathrm{CB}_{1}$ mRNA expression and overall adiposity

(Fig. 5; $r=-0.357, p=0.048$ ).

\section{Discussion}

Seasonally appropriate fat storage has important consequences for survival and reproductive success. Given its role in mammals to promote food intake and lipogenesis (Osei-Hyiaman et al.,

297 2005; Pagotto et al., 2006; Vettor and Pagano, 2009), endocannabinoid signaling may be one 298 mechanism by which rapid modulation of feeding and fattening is achieved in seasonally-

299 breeding birds. In the present study, we used photostimulation of captive birds to induce

300 physiological readiness to reproduce and concurrent fat reduction. We report negative 
301 correlations between adiposity and local 2-AG and OEA concentrations, as well as with

302 hindbrain mRNA expression of $\mathrm{CB}_{1}$ receptors. Our results suggest that different lipid signals

303 serve different functions that may depend on the context under which fat storage occurs.

304 The birds in this study exhibited highly variable and in some cases extremely pronounced

305 fat while under winter-like photoperiods with ad libitum access to food (Fig. 2). The

306 experimental increase in photoperiod was sufficient to trigger an overall reduction in adiposity,

307 as well as gonadal growth and marked steroidogenic capabilities demonstrating that birds were in

308 reproductive condition (Rosvall et al., 2013; Bergeon Burns et al., 2014; Rosvall et al., 2016).

309 Mean fat score of birds at study end remained elevated relative to initial measures in August

310 when birds were on natural long-day photoperiods, suggesting that birds may still have been

311 losing fat at the time of terminal measures. At the time of collection, there remained high

312 variation in adiposity among individuals $(\mathrm{CV}=31.9 \%)$.

313 Such variation in fatness revealed negative relationships between 2-AG concentrations

314 and furcular and abdominal fat mass, indicating that fatter birds have less 2-AG content in fat

315 depots. These findings are consistent with a previous study of seasonal adiposity in which lower

316 2-AG was observed in subcutaneous white adipose tissue of fat, summer-acclimated Siberian

317 hamsters compared with lean, winter-acclimated counterparts (Ho et al., 2012). However, these

318 findings sit in contrast to our predictions and reports of elevated $2-\mathrm{AG}$ concentrations in adipose

319 tissue of obese humans and diet-induced obese mice (Matias et al., 2006). One possible

320 explanation for the discrepancy between studies may be the context in which adiposity occurs. In

321 the context of seasonal adaptation, the negative relationship between endocannabinoid signaling

322 and adiposity may reflect a drive towards fat loss or maintenance once sufficient stores are

323 achieved. Although food intake was not measured in the present study, low 2-AG levels may 
324 reflect an appropriate response for individuals with sufficient fat stores by inhibiting further food

325 intake and lipogenesis, and perhaps even promoting continued fat loss in preparation for

326 breeding. In contrast, high 2-AG levels in clinical obesity may result from dysregulation of

327 regulatory systems that include endocannabinoid signaling. Because our findings provide only a

328 snapshot of dynamic changes in lipid signaling, studies that compare signaling across life-history

329 stages (such as pre- and post- migratory fattening, winter fattening, and/or breeding) are needed

330 to determine how 2-AG concentrations relate to adiposity in natural conditions.

331 No correlations were observed between the other major endocannabinoid ligand, AEA,

332 and any measure of adiposity, indicating a functional separation between endocannabinoid

333 signals. This finding is not surprising, as dissociations between 2-AG and AEA have been

334 reported across a variety of physiological contexts (Di Marzo and Maccarrone, 2008) and

335 concentrations of 2-AG correlated significantly with OEA, but not AEA, in this study. Indeed,

336 concentrations of 2-AG, but not AEA, are significantly elevated in epididymal fat of diet-

337 induced obese mice and in visceral fat of obese humans in comparison with their respective lean

338 controls (Matias et al., 2006). Moreover, each ligand uses a different set of enzymatic machinery

339 (Dinh et al., 2002; Sugiura, 2008), and AEA also interacts with non-cannabinoid receptors

340 (Zygmunt et al., 1999). Our findings suggest that as with mammals, avian 2-AG and AEA are

341 independent from one another in form and function.

342 The patterns we observed in the brain mimic those seen for 2-AG in the periphery:

343 individual juncos demonstrating greater adiposity had less hindbrain $\mathrm{CB}_{1}$ mRNA expression. In

344 mammals, this brain region includes the dorsal vagal complex, which sits at the interface of the

345 gut-brain axis and integrates meal-related satiety signals (Berthoud, 2004). To the extent that

346 mRNA abundance is predictive of receptor expression, less hindbrain $\mathrm{CB}_{1}$ mRNA in fatter birds 
347 is suggestive of less endocannabinoid suppression of satiety signals that emerge from this brain

348 region, thereby promoting satiety. These results may once again reflect a drive to maintain or

349 reduce energy intake in fat birds that have already achieved sufficient energy stores. These

350 results stand in contrast to previous studies in Siberian hamsters that demonstrate

351 endocannabinoid signaling fluctuates seasonally in the hindbrain, such that high summertime

352 adiposity is associated with higher protein levels of hindbrain $\mathrm{CB}_{1}$ and $2-\mathrm{AG}$ relative to lean,

353 winter-like states (Ho, 2011; Ho et al., 2012). Again, further studies that address how hindbrain

$354 \mathrm{CB}_{1}$ signaling relates to appetite and adiposity with greater temporal resolution will help clarify

355 its role in regulating adiposity.

356 Because endocannabinoids are part of a family of biologically active lipids, we examined

357 two additional lipids found in the fat depots that are structurally related to AEA and relevant to

358 energy regulation, although with very different functions than endocannabinoids. OEA and PEA

359 do not act at cannabinoid receptors, but instead activate peroxisome proliferator-activated

360 receptors (PPARs) that regulate lipid metabolism. OEA attenuates body mass gains and

361 stimulates breakdown of fat through PPAR- $\alpha$ (Fu et al., 2003), but its peripherally-based

362 anorectic effects (Rodriguez de Fonseca et al., 2001) may be in part due to its ability to activate

363 GPR119 and elicit glucagon-like peptide-1 (GLP-1) secretion (Lauffer et al., 2009; Moss et al.,

364 2016), which itself has anorectic effects in the hindbrain (Hayes et al., 2008). Thus we predicted

365 that OEA would function in a direction opposite to that of endocannabinoids with respect to fat

366 regulation; instead, we found that OEA concentrations correlated negatively with adiposity,

367 much like our 2-AG findings. Interestingly, OEA concentrations were notably higher than any

368 other lipid examined. While it is not yet known how changes in OEA signaling alter adiposity in

369 birds, these patterns suggest that this compound may be important and should be studied further. 
371 intake in rodents, albeit to a lesser extent than OEA (Rodriguez de Fonseca et al., 2001). In our

372 study, furcular PEA correlated somewhat positively with combined fat mass, but no relationship

373 was observed between abdominal PEA and fat mass. It is presently unclear why patterns of PEA

374 expression contrast with those of OEA given their similar effects on appetite, but these patterns

375 may relate to PEA's involvement in other functions such as inflammation (Solorzano et al.,

376 2009) and analgesia (Calignano et al., 1998). Moreover, relationships between adiposity and the

377 other lipids examined in this study were generally consistent between furcular and abdominal

378 depots, thus the functional significance of these particular findings are unclear.

\section{Conclusions}

380 Considered together, our findings reveal several significant relationships between lipid signaling

381 and adiposity that collectively suggest a role for peripheral and central endocannabinoid

382 signaling in the regulation of fat storage in birds. The patterns we have identified lay the

383 groundwork for future studies that are essential to understanding relationships between fat

384 storage and lipid signaling, including those that ultimately determine how lipid signaling relates

385 to temporal changes in adiposity. Further studies that experimentally manipulate lipid signaling,

386 examine food intake and energy expenditure, and define temporal changes across periods of fat

387 gain and loss will help determine the functional effects of these lipid signals and whether they

388 causally relate to seasonal changes in adiposity. Our study is the first to report OEA and PEA

389 concentrations in birds and demonstrates significant associations between lipid signaling and

390 adiposity. As a consequence, these results add to the wealth of knowledge on the adaptive

391 function of fat regulation in birds by shedding new light on the lesser known, proximate 
392 mechanisms involved in this process. The present study takes an important step towards

393 establishing a potential role for lipid signaling in regulating adiposity in birds.

394 Acknowledgments

395

396 We are grateful to the Black Hills National Forest for access to field site, and to J and C

397 Gorsuch, M Boser, EM Schultz, and C Wood for assistance in South Dakota. B Duncan, R Kiley,

398 MP Peterson, and R Stewart provided valuable assistance. This research was supported by: NIH

399 F32HD068222 to KAR; NIH DA006668 to HBB; NIH T32HD049336; NSF IOS-0919911 to

400 GED; NSF IOS-0909834 to CMBB; NSF IOS-0820055 to EDK; NSF DBI-0851607; and James

401 P. Holland Graduate Fellowship (Indiana University) to NMR. The authors have no conflicts of

402 interest to disclose, and funding sources had no involvement in any aspect of the study design,

403 execution or publication. 
405

406

407

408

409

410

411

412

413

414

415

416

417

418

419

420

421

422

423

424

425

426

427

428

429

430

431

432

433

434

435

436

437

438

439

440

441

442

443

444

445

446

447

448

\section{Literature cited}

Baggott, G.K., 1975. Molt, flight-muscle hypertrophy and premigratory lipid deposition of juvenile willow warbler, Phylloscopus-Trochilus. J. Zool. 175, 299-314.

Baldwin, S.P., Kendeigh, S.C., 1938. Variations in the weight of birds. Auk 55, 416-467.

Bauer, C.M., Needham, K.B., Le, C.N., Stewart, E.C., Graham, J.L., Ketterson, E.D., Greives, T.J., 2016. Hypothalamic-pituitary-adrenal axis activity is not elevated in a songbird (Junco hyemalis) preparing for migration. Gen. Comp. Endocrinol. 232, 60-66.

Bergeon Burns, C.M., Rosvall, K.A., Hahn, T.P., Demas, G.E., Ketterson, E.D., 2014. Examining sources of variation in HPG axis function among individuals and populations of the dark-eyed junco. Horm. Behav. 65:179-187.

Berthold, P., 1993. Bird Migration - A General Survey. Oxford University Press, Oxford.

Berthold, P., 1996. Control of Bird Migration. Chapman and Hall, London.

Berthoud, H.R., 2004. The caudal brainstem and the control of food intake and energy balance, in: Stricker, E.M., Woods, S.C. (Eds.), Neurobiology of Food and Fluid Intake, vol. 14. Springer, New York, pp. 195-240.

Biebach, H., 1996. Energetics of winter and migratory fattening, in: Carey, C. (Ed.), Avian energetics and nutrional ecology. Chapman and Hall, New York, pp. 280-323.

Blem, C.R., 1975. Geographic variation in wing-loading of the House Sparrow. Wilson Bull. 87, 543-549.

Blem, C.R., 1980. The energetics of migration, in: Gauthreaux, S.A. (Ed.), Animal Migration, Orientation, and Navigation. Academic Press, London, pp. 175-224.

Boswell, T., Richardson, R.D., Seeley, R.J., Ramenofsky, M., Wingfield, J.C., Friedman, M.I., Woods, S.C., 1995. Regulation of food intake by metabolic fuels in white-crowned sparrows. Am. J. Physiol. Regul. Integr. Comp. Physiol. 269, R1462-R1468.

Bradshaw, H.B., Rimmerman, N., Krey, J.F., Walker, J.M., 2006. Sex and hormonal cycle differences in rat brain levels of pain-related cannabimimetic lipid mediators. Am. J. Physiol. Regul. Integr. Comp. Physiol. 291, R349-R358.

Buntin, J.D., Tesch, D., 1985. Effects of intracranial prolactin administration on maintenance of incubation readiness, ingestive behavior, and gonadal condition in ring doves. Horm. Behav. 19, 188-203.

Calignano, A., La Rana, G., Giuffrida, A., Piomelli, D., 1998. Control of pain initiation by endogenous cannabinoids. Nature 394, 277-281.

Cluny, N.L., Vemuri, V.K., Chambers, A.P., Limebeer, C.L., Bedard, H., Wood, J.T., Lutz, B., Zimmer, A., Parker, L.A., Makriyannis, A., Sharkey, K.A., 2010. A novel peripherally restricted cannabinoid receptor antagonist, AM6545, reduces food intake and body weight, but does not cause malaise, in rodents. Br. J. Pharmacol. 161, 629-642.

Cota, D., Marsicano, G., Tschop, M., Grubler, Y., Flachskamm, C., Schubert, M., Auer, D., Yassouridis, A., Thone-Reineke, C., Ortmann, S., Tomassoni, F., Cervino, C., Nisoli, E., Linthorst, A.C., Pasquali, R., Lutz, B., Stalla, G.K., Pagotto, U., 2003. The endogenous cannabinoid system affects energy balance via central orexigenic drive and peripheral lipogenesis. J. Clin. Invest. 112, 423-431.

Dawson, A., King, V.M., Bentley, G.E., Ball, G.F., 2001. Photoperiodic control of seasonality in birds. J. Biol. Rhythms 16, 365-380. 
Deviche, P.E., 1995. Androgen regulation of avian premigratory hyperphagia and fattening: from eco-physiology to neuroendocrinology. Am. Zool. 35, 234-245.

Di Marzo, V., De Petrocellis, L., Bisogno, T., 2005. The biosynthesis, fate and pharmacological properties of endocannabinoids, in: Pertwee, R.G. (Ed.), Handbook of Experimental Pharmacology, Springer-Verlag, Heidelberg, Germany, pp. 147-185.

Di Marzo, V., Maccarrone, M., 2008. FAAH and anandamide: is 2-AG really the odd one out? Trends Pharmacol. Sci. 29, 229-233.

Dickens, M.J,. Vecchiarelli, H.A., Hill, M.N., Bentley, G.E., 2015. Endocannabinoid Signaling in the stress response of male and female songbirds. Endocrinology 156, 4649-4659.

Dinh, T.P., Freund, T.F., Piomelli, D., 2002. A role for monoglyceride lipase in 2arachidonoylglycerol inactivation. Chem. Phys. Lipids 121, 149-158.

eBird, 2016. An online database of bird distribution and abundance. http://www.ebird.org/content/ebird/ (accessed 28.06.16)

Freed, L.A., 1981. Loss of mass in breeding wrens: stress or adaptation? Ecology 62, 1179-1186.

Fu, J., Gaetani, S., Oveisi, F., Lo Verme, J., Serrano, A., de Fonseca, F.R., Rosengarth, A., Luecke, H., Di Giacomo, B., Tarzia, G., Piomelli, D., 2003. Oleylethanolamide regulates feeding and body weight through activation of the nuclear receptor PPAR-alpha. Nature 425, 90-93.

Fudickar, A.M., Greives, T.J., Atwell, J.W., Stricker, C.A., Ketterson, E.D., 2016. Reproductive allochrony in seasonally sympatric populations maintained by differential response to photoperiod: implications for population divergence and response to climate change. Am. Nat. 187, 436-446.

Gray, J.M., Yarian, D., Ramenofsky, M., 1990. Corticosterone, foraging behavior, and metabolism in dark-eyed juncos, Junco hyemalis. Gen. Comp. Endocrinol. 79, 375-384.

Gwinner, E., 1986. Circannual rhythms endogenous circadian clocks in the organization of seasonal processes. Springer, Berlin Heidelberg New York.

Hayes, M.R., Skibicka, K.P., Grill, H.J., 2008. Caudal brainstem processing is sufficient for behavioral, sympathetic, and parasympathetic responses driven by peripheral and hindbrain glucagon-like-peptide-1 receptor stimulation. Endocrinology 149, 4059-4068.

Ho, J.M., 2011. Seasonal changes in endocannabinoid signaling and energy regulation. Indiana University, Bloomington.

Ho, J.M., Smith, N.S., Adams, S.A., Bradshaw, H.B., Demas, G.E., 2012. Photoperiodic changes in endocannabinoid levels and energetic responses to altered signalling at CB1 receptors in Siberian hamsters. J. Neuroendocrinol. 24, 1030-1039.

Holberton, R.L., Boswell, T., Hunter, M.J., 2008. Circulating prolactin and corticosterone concentrations during the development of migratory condition in the dark-eyed junco, Junco hyemalis. Gen. Comp. Endocrinol. 155, 641-649.

Holberton, R.L., Dufty, A.M., Jr., 2005. Hormone patterns and variation in life history strategies of migratory and non-migratory birds, in: Marra, P.P., Greenberg, R., (Eds.), Birds of Two Worlds: The Ecology and Evolution of Migratory Birds. Johns Hopkins Press, Baltimore, pp. 90-302.

Holberton, R.L., Wilson, C.M., Hunter, M.J., Cash, W.B., Sims, C.G., 2007. The role of corticosterone in supporting migratory lipogenesis in the dark-eyed junco, Junco hyemalis: a model for central and peripheral regulation. Physiol. Biochem. Zool. 80, 125137. 
Jawor J.M., McGlothlin, J.W., Casto, J.M., Greives, T.J., Snajdr, E.A., Bentley, G.E., Ketterson, E.D., 2006. Seasonal and individual variation in response to GnRH challenge in male dark-eyed juncos (Junco hyemalis). Gen. Comp. Endocrinol. 149, 182-189.

Jbilo, O., Ravinet-Trillou, C., Arnone, M., Buisson, I., Bribes, E., Peleraux, A., Penarier, G., Soubrie, P., Le Fur, G., Galiegue, S., Casellas, P., 2005. The CB1 receptor antagonist rimonabant reverses the diet-induced obesity phenotype through the regulation of lipolysis and energy balance. FASEB J 19, 1567-1569.

Jo, Y.H., Chen, Y.J., Chua, S.C., Jr., Talmage, D.A., Role, L.W., 2005. Integration of endocannabinoid and leptin signaling in an appetite-related neural circuit. Neuron 48, 1055-1066.

King, J.R., 1972. Adaptive periodic fat storage by birds. Proc. Int. Ornithol. Congr. 15, 200-217.

King, J.R., Barker, S., Farner, D.S., 1963. A comparison of energy reserves during autumnal and vernal migratory periods in white-crowned sparrow, Zonotrichia leucophrys gambelii. Ecology 44, 513-521.

Lauffer, L.M., Iakoubov, R., Brubaker, P.L., 2009. GPR119 is essential for oleoylethanolamideinduced glucagon-like peptide-1 secretion from the intestinal enteroendocrine L-cell. Diabetes 58, 1058-1066.

Lima, S.L., 1986. Predation risk and unpredictable feeding conditions: determinants of body mass in birds. Ecology 67, 366-376.

Lofts, B., Marshall, A.J., 1961. Zugunruhe activity in castrated bramblings (Fringilla montifringilla). Ibis 103, 189-194.

LoVerme, J., Russo, R., La Rana, G., Fu, J., Farthing, J., Mattace-Raso, G., Meli, R., Hohmann, A., Calignano, A., Piomelli, D., 2006. Rapid broad-spectrum analgesia through activation of peroxisome proliferator-activated receptor-alpha. J. Pharm. Exp. Ther. 319, 10511061.

Matias, I., Gonthier, M.P., Orlando, P., Martiadis, V., De Petrocellis, L., Cervino, C., Petrosino, S., Hoareau, L., Festy, F., Pasquali, R., Roche, R., Maj, M., Pagotto, U., Monteleone, P., Di Marzo, V., 2006. Regulation, function, and dysregulation of endocannabinoids in models of adipose and beta-pancreatic cells and in obesity and hyperglycemia. J. Clin. Endocrinol. Metab. 91, 3171-3180.

Meier, A.H., Farner, D.S., 1964. A possible endocrine basis for premigratory fattening in the white-crowned sparrow, Zonotrichia leucophrys gambelii (Nuttall). Gen. Comp. Endocrinol. 4, 584-595.

Morton, M.L., Mewalt, L.R., 1962. Some effects of castration on a migratory sparrow (Zonotrichia atricapilla). Physiol. Zool. 35, 237-247.

Moss, C.E., Glass, L.L., Diakogiannaki, E., Pais, R., Lenaghan, C., Smith, D.M., Wedin, M., Bohlooly, Y.M., Gribble, F.M., Reimann, F., 2016. Lipid derivatives activate GPR119 and trigger GLP-1 secretion in primary murine L-cells. Peptides 77, 16-20.

Nolan, V., Ketterson, E.D., 1983. An analysis of body mass, wing length, and visible fat deposits of dark-eyed juncos wintering at different latitudes. Wilson Bull. 95, 603-620.

Novoseletsky, N., Nussinovitch, A., Friedman-Einat, M., 2011. Attenuation of food intake in chicks by an inverse agonist of cannabinoid receptor 1 administered by either injection or ingestion in hydrocolloid carriers. Gen. Comp. Endocrinol. 170, 522-527.

Osei-Hyiaman, D., DePetrillo, M., Pacher, P., Liu, J., Radaeva, S., Batkai, S., Harvey-White, J., Mackie, K., Offertaler, L., Wang, L., Kunos, G., 2005. Endocannabinoid activation at 
hepatic CB1 receptors stimulates fatty acid synthesis and contributes to diet-induced obesity. J. Clin. Invest. 115, 1298-1305.

Pagano, C., Pilon, C., Calcagno, A., Urbanet, R., Rossato, M., Milan, G., Bianchi, K., Rizzuto, R., Bernante, P., Federspil, G., Vettor, R., 2007. The endogenous cannabinoid system stimulates glucose uptake in human fat cells via phosphatidylinositol 3-kinase and calcium-dependent mechanisms. J. Clin. Endocrinol. Metab. 92, 4810-4819.

Pagotto, U., Marsicano, G., Cota, D., Lutz, B., Pasquali, R., 2006. The emerging role of the endocannabinoid system in endocrine regulation and energy balance. Endocr. Rev. 27, 73-100.

Piersma, T., Jukema, J., 1990. Budgeting the flight of a long-distance migrant - changes in nutrient reserve levels of bar-tailed godwits at successive spring staging sites. Ardea 78, 315-337.

Quarta, C., Bellocchio, L., Mancini, G., Mazza, R., Cervino, C., Braulke, L.J., Fekete, C., Latorre, R., Nanni, C., Bucci, M., Clemens, L.E., Heldmaier, G., Watanabe, M., LesteLassere, T., Maitre, M., Tedesco, L., Fanelli, F., Reuss, S., Klaus, S., Srivastava, R.K., Monory, K., Valerio, A., Grandis, A., De Giorgio, R., Pasquali, R., Nisoli, E., Cota, D., Lutz, B., Marsicano, G., Pagotto, U., 2010. CB(1) signaling in forebrain and sympathetic neurons is a key determinant of endocannabinoid actions on energy balance. Cell. Metab. 11, 273-285.

Ramakrishnan, S., Strader, A.D., Wimpee, B., Chen, P., Smith, M.S., Buntin, J.D., 2007. Evidence for increased neuropeptide $\mathrm{Y}$ synthesis in mediobasal hypothalamus in relation to parental hyperphagia and gonadal activation in breeding ring doves. J. Neuroendocrinol. 19, 163-171.

Ramenofsky, M., Savard, R., Greenwood, M.R.C., 1999. Seasonal and diel transitions in physiology and behavior in the migratory dark-eyed junco. Comp. Biochem. Physiol. A Mol. Integr. Physiol. 122, 385-397.

Rodriguez de Fonseca, F., Navarro, M., Gomez, R., Escuredo, L., Nava, F., Fu, J., MurilloRodriguez, E., Giuffrida, A., LoVerme, J., Gaetani, S., Kathuria, S., Gall, C., Piomelli, D., 2001. An anorexic lipid mediator regulated by feeding. Nature 414, 209-212.

Rogers, C.M., 1995. Experimental evidence for temperature-dependent winter lipid storage in the dark-eyed junco (Junco hyemalis oreganus) and song sparrow (Melospiza melodia morphna). Physiol. Zool. 68, 277-289.

Rogers, C.M., 1995. Testing optimal body mass theory: Evidence for cost of fat in wintering birds. Ecosphere 6(4): 55.

Rogers, C.M., Ramenofsky, M., Ketterson, E.D., Nolan, V., Wingfield, J.C., 1993. Plasma corticosterone, adrenal mass, winter weather, and season in nonbreeding populations of dark-eyed juncos (Junco hyemalis hyemalis). Auk 110, 279-285.

Rogers, C.M., Smith, J.N.M., 1993. Life-history theory in the nonbreeding period: trade-offs in avian fat reserves? Ecology 74, 419-426.

Rosvall, K.A., Bergeon Burns, C.M., Hahn, T.P., Ketterson, E.D., 2013. Sources of variation in HPG axis reactivity and individually consistent elevation of sex steroids in a female songbird. Gen. Comp. Endocrinol. 194, 230-239.

Rosvall, K.A., Bergeon Burns, C.M., Jayaratna, S.P., Ketterson, E.D., 2016. Divergence along the gonadal steroidogenic pathway: Implications for hormone-mediated phenotypic evolution. Horm. Behav. 84, 1-8. 
Schmittgen, T.D., Livak, K.J., 2008. Analyzing real-time PCR data by the comparative C(T) method. Nat. Protoc. 3, 1101-1108.

Schwabl, H., Farner, D.S., 1989. Endocrine and environmental-control of vernal migration in male white-crowned sparrows, Zonotrichia-leucophrys-gambelii. Physiol. Zool. 62, 1-10.

Solorzano, C., Zhu, C., Battista, N., Astarita, G., Lodola, A., Rivara, S., Mor, M., Russo, R., Maccarrone, M., Antonietti, F., Duranti, A., Tontini, A., Cuzzocrea, S., Tarzia, G., Piomelli, D., 2009. Selective N-acylethanolamine-hydrolyzing acid amidase inhibition reveals a key role for endogenous palmitoylethanolamide in inflammation. Proc. Natl. Acad. Sci. USA 106, 20966-20971.

Soma, K.K., Bindra, R.K., Gee, J., Wingfield, J.C., Schlinger, B.A., 1999. Androgenmetabolizing enzymes show region-specific changes across the breeding season in the brain of a wild songbird. J. Neurobiol. 41, 176-188.

Stetson, M.H., Erickson, J.E., 1972. Hormonal-control of photoperiodically induced fat deposition in white-crowned sparrows. Gen. Comp. Endocrinol. 19, 355-362.

Sugiura, T., 2008. Biosynthesis of anandamide and 2-arachidonylglycerol, in: Köfalvi, A., (Ed.) Cannabinoids and the Brain. Springer Science + Business Media LLC, Coimbra, Portugal pp. 15-30.

Tam, J., Vemuri, V.K., Liu, J., Batkai, S., Mukhopadhyay, B., Godlewski, G., Osei-Hyiaman, D., Ohnuma, S., Ambudkar, S.V., Pickel, J., Makriyannis, A., Kunos, G., 2010. Peripheral CB1 cannabinoid receptor blockade improves cardiometabolic risk in mouse models of obesity. J. Clin. Invest. 120, 2953-2966.

Totzke, U., Hubinger, A., Bairlein, F., 1997. A role for pancreatic hormones in the regulation of autumnal fat deposition of the garden warbler (Sylvia borin)? Gen. Comp. Endocrinol. 107, 166-171.

Vettor, R., Pagano, C., 2009. The role of the endocannabinoid system in lipogenesis and fatty acid metabolism. Best Pract. Res. Clin. Endocrinol. Metab. 23, 51-63.

Whitney, N.R., 1968. White-winged junco, in: Austin, O.L. (Ed.), Life Histories of North American Cardinals, Grosbeaks, Buntings, Towhees, Finches, Sparrows, and Their Allies Pt 2 (Vol. 237) U.S. Natl. Mus. Bull., pp. 1021-1029.

Williams, T.D., 2012. Physiological Adaptations for Breeding in Birds. Princeton University Press, Princeton, NJ.

Witter, M.S., Swaddle, J.P., Cuthill, I.C., 1995. Periodic food availability and strategic regulation of body-mass in the European starling, Sturnus-vulgaris. Funct. Ecol. 9, 568-574.

Zygmunt, P.M., Petersson, J., Andersson, D.A., Chuang, H., Sorgard, M., Di Marzo, V., Julius, D., Hogestatt, E.D., 1999. Vanilloid receptors on sensory nerves mediate the vasodilator action of anandamide. Nature 400, 452-457. 
Table 1. Criteria used to assign fat scores. ${ }^{*}$ some scores were assigned an additional + or -0.25 for greater accuracy

\begin{tabular}{|c|l|}
\hline Fat score* & Criterion \\
\hline 1 & Fat present in abdomen or furculum (one place) \\
\hline 2 & Fat present in both abdomen and furculum \\
\hline 3 & Fat flush with body curvature in abdomen or furculum (one place) \\
\hline 4 & Fat bulging in abdomen or furculum (one place) \\
\hline 5 & Fat bulging in both abdomen and furculum \\
\hline
\end{tabular}




\section{Figure legends}

Figure 1. Relationships between visual fat score and combined mass of abdominal and furcular fat depots (A) and between abdominal and furcular fat mass (B). $p<0.05$, Pearson's correlation coefficient and Spearman's rho.

Figure 2. Relationship between adiposity and date, as birds gain fat over-winter and lose fat as they enter breeding condition. Error bars represent one standard error from the mean. The shaded bar highlights the period of light advancement, and the dashed line indicates when birds reached a long-day photoperiod (16L:8D). Although the sexes differed in overwinter fat levels, males (gray) and females (black), they did not differ after light advancement. Repeated measures MANOVA, Date: $F=33.05, p<0.001$; Sex: $F=7.38, p=0.012$; Sex*Date: $F=2.926, p=$ 0.008. Post-hoc $t$-test compared sexes in April: $t=1.12, p=0.27$.

Figure 3. Relationships between combined abdominal and furcular fat mass and furcular levels of 2-arachidonoylglycerol (2-AG) (A), anandamide (AEA) (B), oleoylethanolamide (OEA) (C), and palmitoylethanolamide (PEA) (D). Pearson's correlation coefficient.

Figure 4. Relationships between combined abdominal and furcular fat mass and abdominal levels of 2-arachidonoylglycerol (2-AG) (A), anandamide (AEA) (B), oleoylethanolamide (OEA) (C), and palmitoylethanolamide (PEA) (D). Pearson's correlation coefficient.

Figure 5. Relationship between combined abdominal and furcular fat mass and hindbrain $\mathrm{CB}_{1}$ mRNA expression levels. Expression levels were calculated relative to those of glyceraldehyde3 -phosphate dehydrogenase (GAPDH) and normalized to calibrator values. $p<0.05$, Pearson's correlation coefficient. 
Figure 1

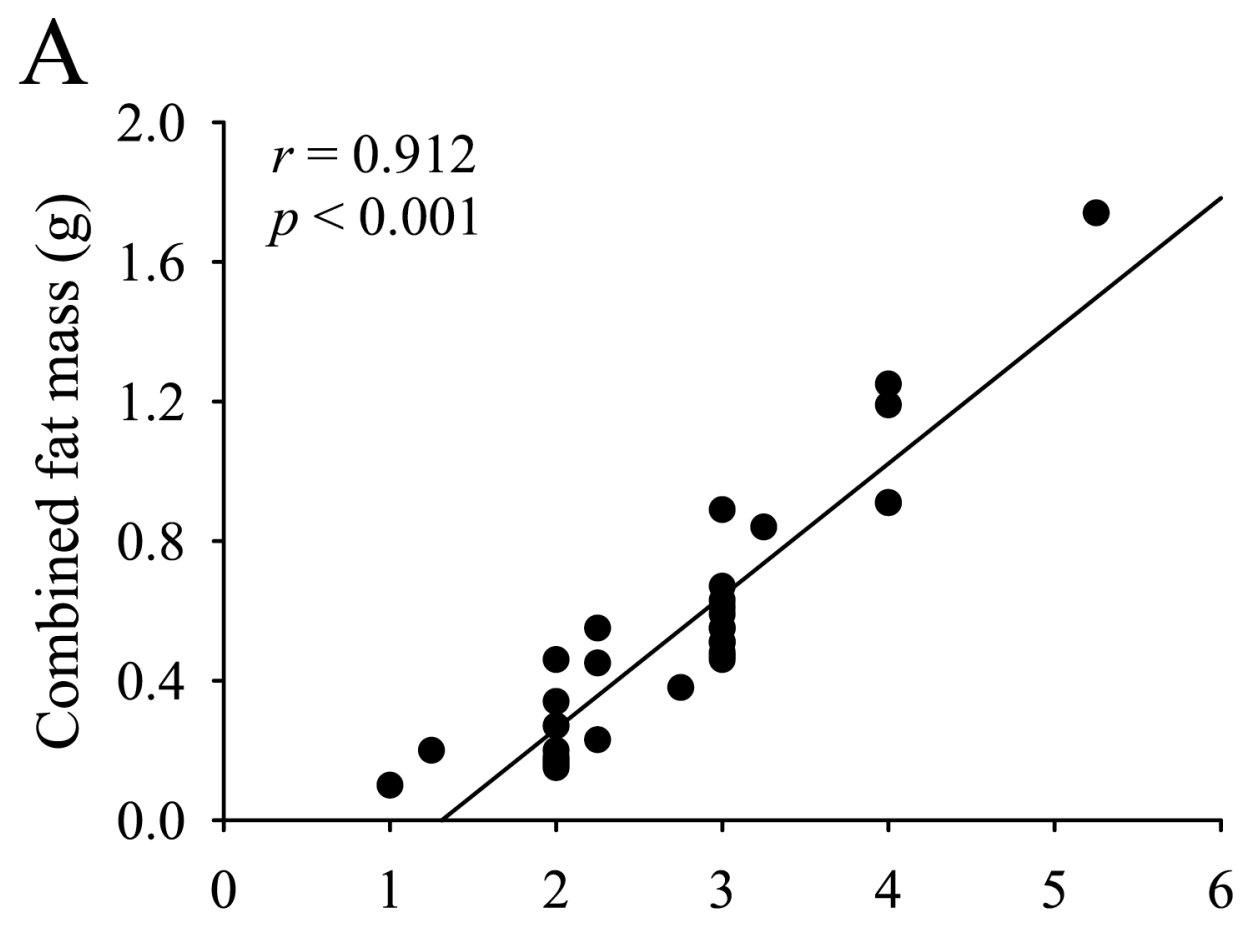

Fat score

B

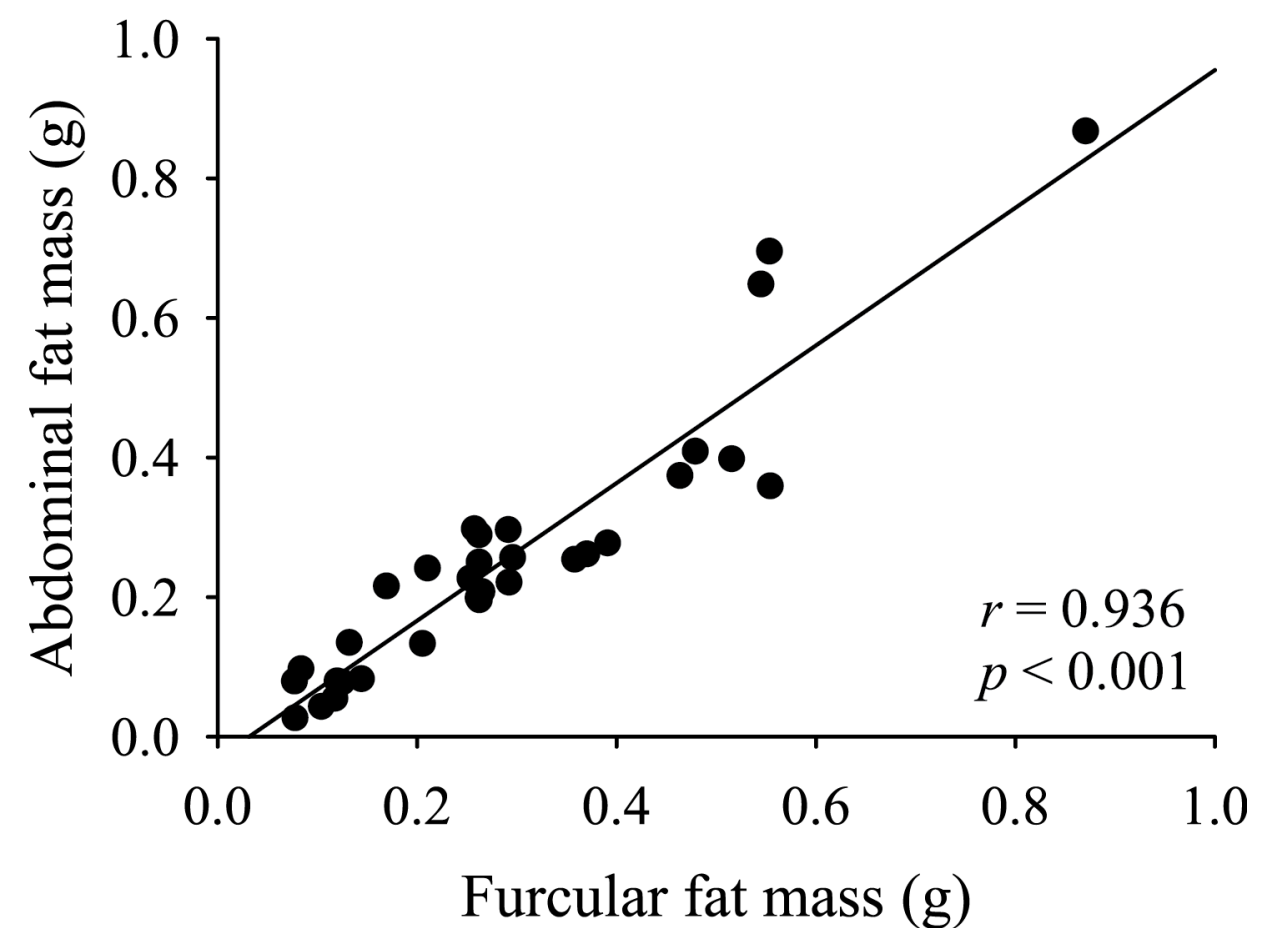


Figure 2

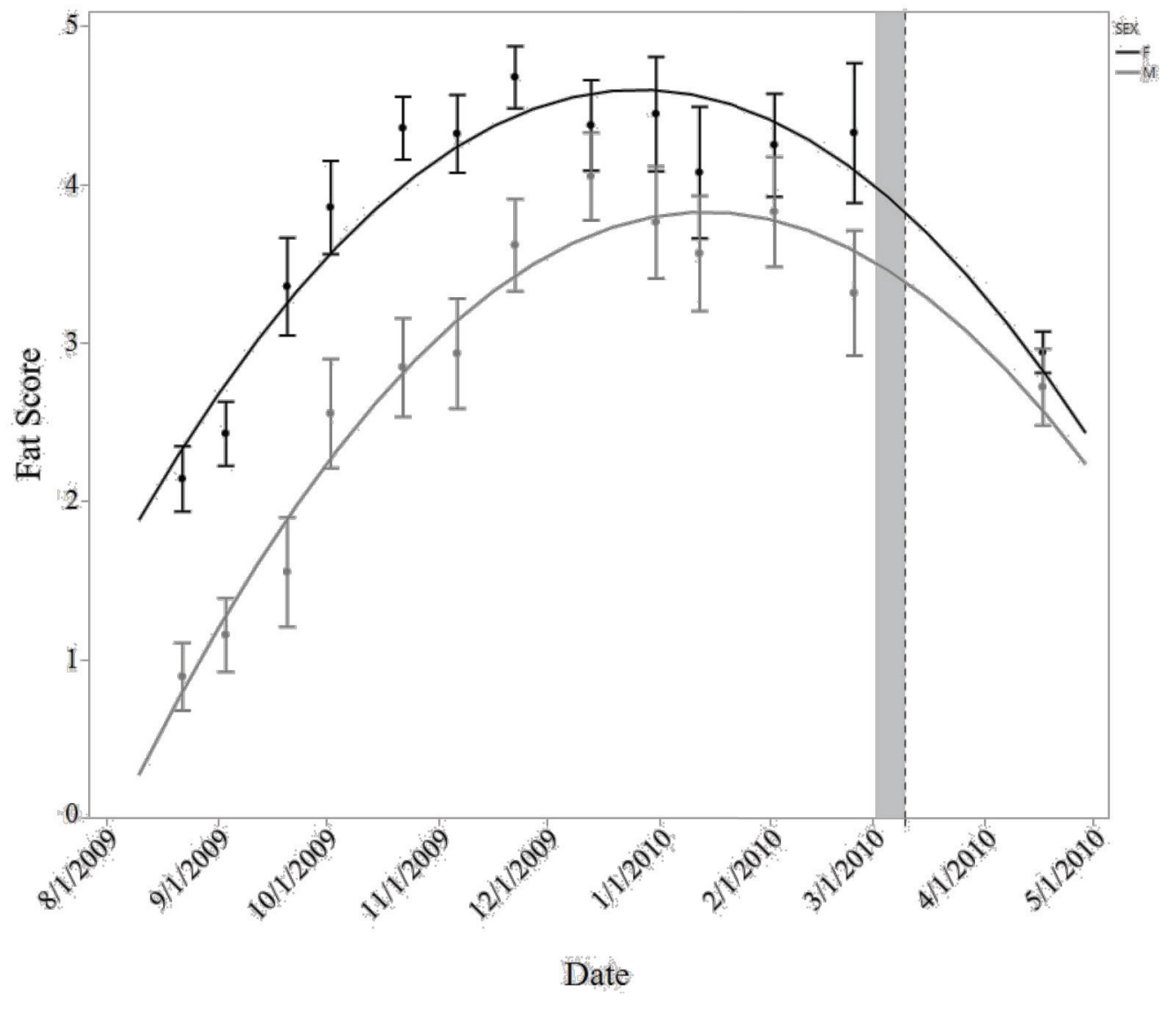


Figure 3
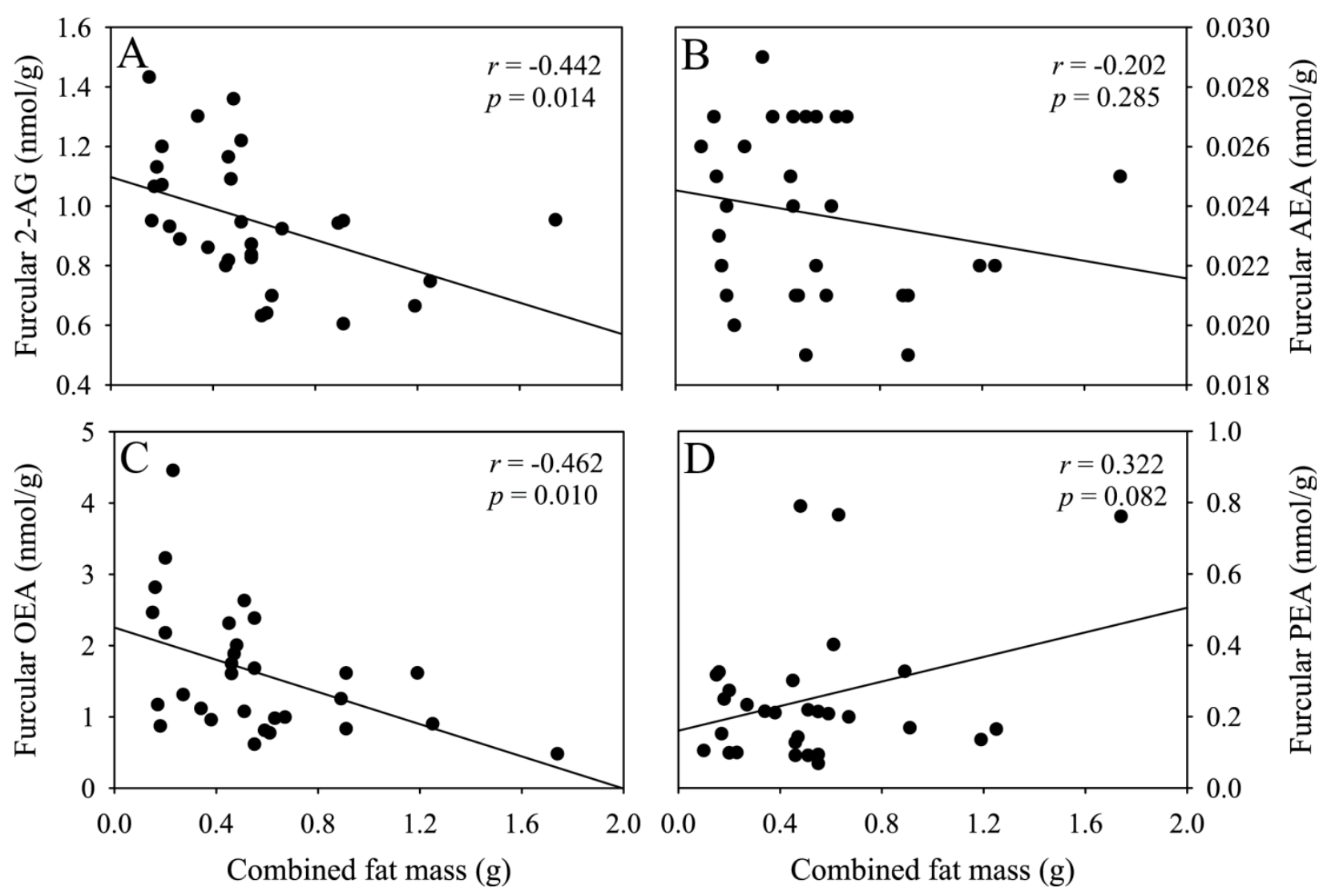
Figure 4
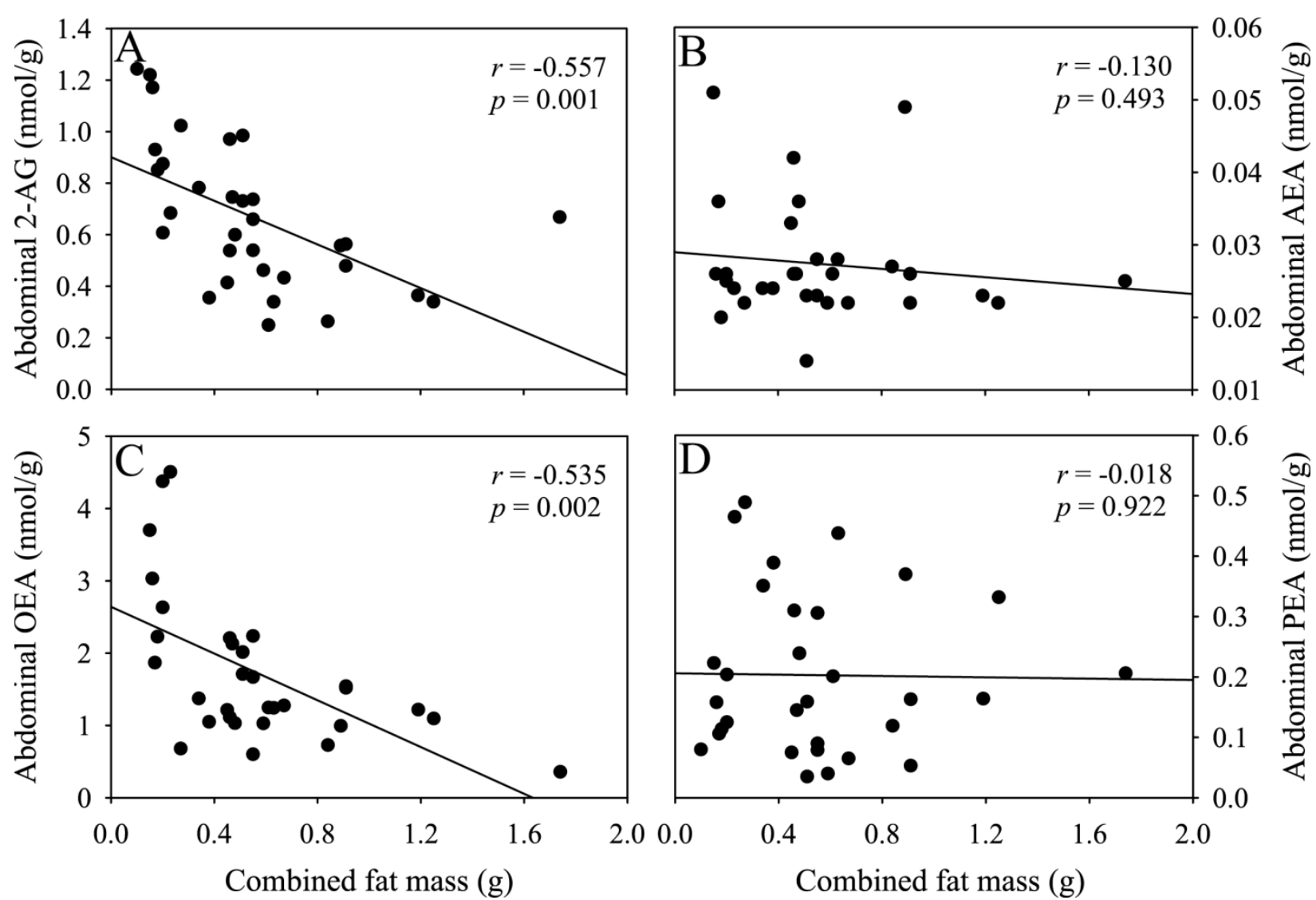
Figure 5

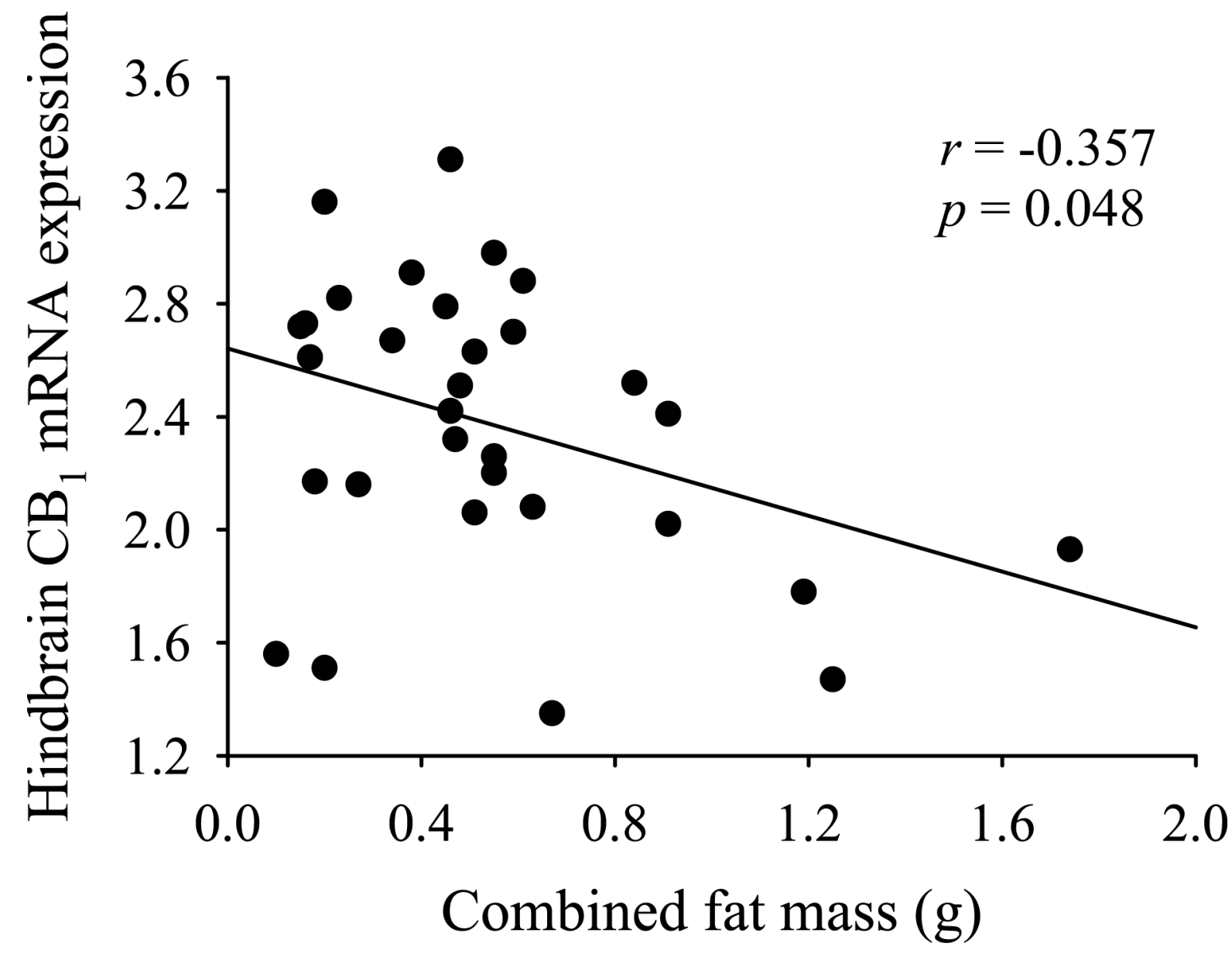

